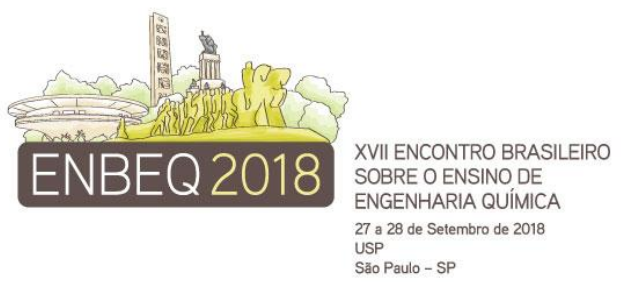

\title{
CULTIVO DA MICROALGA Chlorella sorokiniana UTILIZANDO EFLUENTE DE LATICÍNIO COMO MEIO DE CULTIVO ALTERNATIVO
}

\author{
RESENDE AR ${ }^{1}$, DE PAULA Jr. $\mathrm{PH}^{2}$, CASTRO GP ${ }^{3}$ e OLIVEIRA Jr. EN ${ }^{4}$ \\ ${ }^{1}$ Universidade Federal de São João Del Rei, Programa de Pós-graduação em Tecnologias \\ para o Desenvolvimento Sustentável \\ ${ }^{2}$ Universidade Federal de São João Del Rei, Campus Alto Paraopeba \\ ${ }^{3}$ Universidade Federal de São João Del Rei, Campus Alto Paraopeba \\ ${ }^{4}$ Universidade Federal de São João Del Rei, Departamento de Química, Biotecnologia e \\ Engenharia de Bioprocessos \\ E-mail para contato: resende.amanda93@hotmail.com
}

RESUMO - A utilização de microalgas como matéria-prima para vários processos têm aumentado nos últimos anos devido aos diversos produtos resultantes do seu metabolismo. É possivel associar a produção de biomassa microalgal à remoção de contaminantes em efluentes, visto que o metabolismo de crescimento das microalgas utiliza a matéria orgânica e os nutrientes presentes nos efluentes, como o soro de leite, resíduo da indústria de laticínios. Assim, o principal objetivo desta pesquisa foi avaliar a produção de biomassa microalgal e a remoção de matéria orgânica por parte da microalga Chlorella sorokiniana em um meio contento soro de leite e meio basal Inthorn, simulando um efluente de laticínio. Foi realizado um Planejamento Experimental DCCR $2^{2}$ a fim de ser obter e analisar a influência das variáveis soro de leite (0 a 40\% v/v) e meio basal Inthorn (0 a 60\% v/v) na produção final de biomassa microalgal, além disso, foi avaliada a remoção de matéria orgânica, através da análise de DQO e da lactose. Os resultados mostraram que foi alcançada a maior produção de biomassa microalgal $(0,57 \mathrm{~g} / 100 \mathrm{~mL})$ a partir do meio composto por $20 \%(\mathrm{v} / \mathrm{v})$ de soro de leite e $30 \%(\mathrm{v} / \mathrm{v})$ de meio basal. Além disso, esse ensaio gerou uma remoção de DQO do meio de $86 \%$, e uma remoção de lactose de $98 \%$. Percebe-se por meio dos resultados obtidos que foi possível se obter uma alta produção de biomassa microalgal bem como alta remoção de contaminante do meio a partir do cultivo de microalga em efluente de laticínio, mostrando que é viável aliar a produção de biomassa microalgal ao tratamento de efluentes.

\section{INTRODUÇÃO}

A utilização de microalgas em processos de tratamento de efluentes é uma forma de aplicação destes microrganismos. Com base no metabolismo de crescimento das microalgas, que necessita de carbono orgânico e formas inorgânicas de nitrogênio e fósforo, é possível associar a produção de biomassa à remoção de contaminantes em efluentes (SILVA, 2014). 


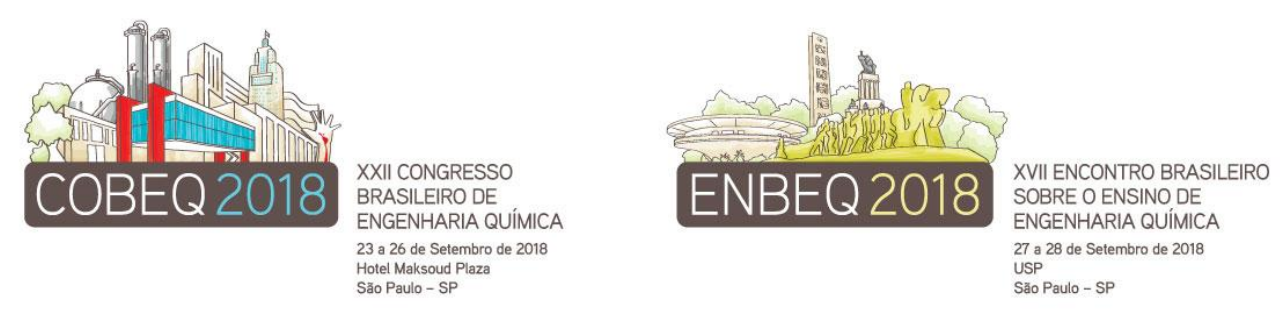

Além disso, microalgas estão atualmente recebendo muita atenção devido a sua gama de utilidades, a aplicação biotecnológica das microalgas é diversa. Esses microrganismos são fonte de quantidades relevantes de lipídeos, proteínas e carboidratos que podem ser convertidos em produtos de interesse comercial.

Assim, a integração da produção de biomassa de microalgas e tratamento de efluente é considerada uma estratégia viável independente de sua finalidade. Nesse contexto, a presente pesquisa se propôs a avaliar a produção de biomassa microalgal e a remoção de matéria orgânica do meio por parte da microalga Chlorella sorokiniana em um meio contendo soro de leite, simulando um efluente de laticínio.

\section{METODOLOGIA}

\subsection{Microrganismos e Soro de leite}

A cepa da Chlorella sorokiniana foi cordialmente cedida pelo Professor Dr. Eduardo Jacob Lopes, do Departamento de Tecnologia e Ciência dos Alimentos da Universidade Federal de Santa Maria (UFSM). O soro de leite foi fornecido pelo Laticínio Vale do Ipê Ltda, que fica na Zona Rural, da cidade de Ouro Branco - MG.

\subsection{Planejamento experimental}

Foi realizado um planejamento estatístico DCCR (Delineamento Composto Central Rotacional) fracionado $2^{2}$ com 4 pontos axiais e triplicata no ponto central, totalizando 11 ensaios, sendo o soro de leite variando de uma concentração de 0 a $40 \%$ (v/v) e o meio basal (INTHORN et al. 2002) variando de uma concentração de 0 a $60 \%$ (v/v). O cultivo se deu em fotobioreatores de baixo custo feitos com garrafas PET transparentes, a uma aeração de $1 \mathrm{~L} /$ min, a uma luminosidade de $130 \pm 5$ klux e à temperatura ambiente.

A realização do planejamento experimental objetivou a obtenção das condições otimizadas de produção de biomassa microalgal e remoção de matéria orgânica, através da redução de DQO e lactose do meio de cultivo alternativo. Para isto, a microalga foi cultivada nos meios alternativos contendo diferentes concentrações de meio basal e soro de leite. $\mathrm{O}$ crescimento da biomassa foi monitorado de 3 em 3 dias através da densidade ótica das culturas em espectrofotômetro à $600 \mathrm{~nm}$ e de uma curva de calibração relacionando D.O e massa seca.

Para a determinação da Demanda Química de Oxigênio (DQO), utilizou-se a metodologia proposta pelo Standart Methods for the examination of water and wastewater (APHA, 2005). A concentração de lactose $(\mathrm{mg} / \mathrm{L})$ foi determinada de acordo com o método de ácido denitrossalicílico (DNS), segundo MILLER (1959). Ambos os parâmetros foram analisados no dia inicial e de $3 \mathrm{em} 3$ dias ao longo do experimento.

\section{RESULTADOS E DISCUSSÃO}

As variáveis resposta dos cultivos do planejamento experimental referentes à produção de biomassa microalgal $(\mathrm{g} / 100 \mathrm{~mL})$, remoção de DQO (\%) e de lactose (\%) estão representadas na Tabela 1 . 

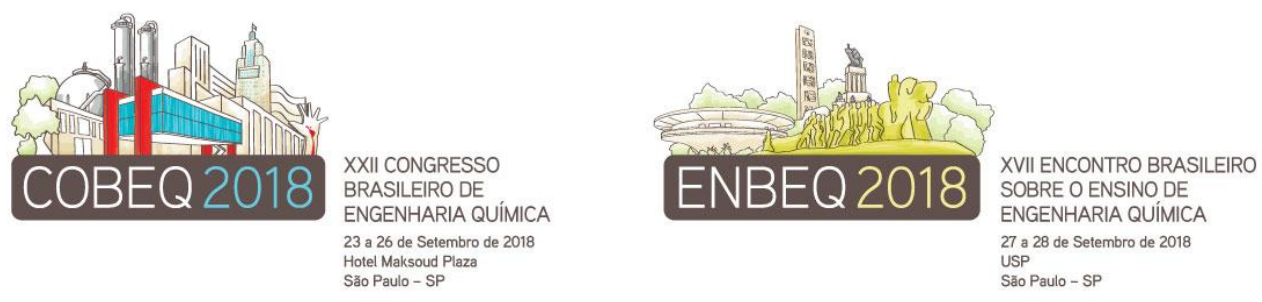

Tabela 1 - Resultados obtidos no planejamento experimental em relação à biomassa microalgal gerada, remoção de DQO e de lactose

\begin{tabular}{cccccc}
\hline Ensaio & $\begin{array}{c}\text { Soro de } \\
\text { leite } \\
(\boldsymbol{\%} \text { v/v) }\end{array}$ & $\begin{array}{c}\text { Meio basal } \\
\text { (INTHORN et } \\
\text { al., 2002) } \\
(\% \text { v/v) }\end{array}$ & $\begin{array}{c}\text { Biomassa } \\
\text { microalgal (g/100 } \\
\text { mL de meio de } \\
\text { cultivo) }\end{array}$ & $\begin{array}{c}\text { Redução de } \\
\text { DQO (\%) }\end{array}$ & $\begin{array}{c}\text { Redução da } \\
\text { concentração de } \\
\text { lactose (\%) }\end{array}$ \\
\hline 1 & $-1(06)$ & $-1(09)$ & 75 & 0,201 & 54,2 \\
2 & $-1(06)$ & $+1(51)$ & 33 & 0,357 & 47 \\
3 & $+1(34)$ & $-1(09)$ & 47 & 0,494 & 79 \\
4 & $+1(34)$ & $+1(51)$ & 05 & 0,455 & 86,4 \\
5 & $-1,41(0)$ & $0(30)$ & 60 & 0,103 & - \\
6 & $+1,41(40)$ & $0(30)$ & 20 & 0,301 & 60,4 \\
7 & $0(20)$ & $-1,41(0)$ & 70 & 0,479 & 79,1 \\
8 & $0(20)$ & $+1,41(60)$ & 10 & 0,355 & 82,7 \\
$9 *$ & $0(20)$ & $0(30)$ & 40 & 0,556 & 86,2 \\
$10 *$ & $0(20)$ & $0(30)$ & 40 & 0,576 & 89,8 \\
$11 *$ & $(20)$ & $0(30)$ & 40 & 0,571 & 84,2 \\
\hline
\end{tabular}

Verifica-se que todos os meios que continham soro de leite apresentaram maior produção de biomassa que o meio que continha somente meio basal (Ensaio 5). Destaca-se que o Ensaio 7 continha apenas soro de leite $(20 \% \mathrm{v} / \mathrm{v})$, produziu uma concentração de biomassa microalgal $(0,479 \mathrm{~g} / 100 \mathrm{~mL}) 4,6$ vezes maior que o ensaio $5(0,103 \mathrm{~g} / 100 \mathrm{~mL})$, que continha apenas meio basal $(30 \% \mathrm{v} / \mathrm{v})$. Porém, o ensaio 6 , que continha a maior concentração de soro de leite $(40 \% \mathrm{v} / \mathrm{v})$ produziu menor biomassa que as condições que com $20 \% \mathrm{v} / \mathrm{v}$ e $34 \% \mathrm{v} / \mathrm{v}$, indicando que com uma quantidade maior de soro de leite, o crescimento torna-se limitado, como acontece em concentrações pequenas $(6 \% \mathrm{v} / \mathrm{v})$. Verifica-se através dos resultados que a melhor condição de crescimento se dá no ponto central (Ensaios 9, 10 e 11 com a média de 0,5676 $\pm 0,040 \mathrm{~g} / 100 \mathrm{~mL} . \mathrm{L})$, que continham $20 \% \mathrm{v} / \mathrm{v}$ de soro de leite e $30 \%$ v/v de meio basal, sendo esta biomassa obtida 5,5 vezes maior do que a do Ensaio 5 (0,103 $\mathrm{g} / 100 \mathrm{~mL}$ ), que foi cultivado somente sob condições fotoautotróficas.

Tal resultado entra em consonância com o que foi obtido por.Abreu et al. (2012), que realizaram o cultivo mixotrófico de Chlorella vulgaris usando efluente da indústria de laticínios como fonte de carbono e obtiveram também os valores mais altos de biomassa alcançados em culturas mixotróficas que continham soro de leite, obtendo-se uma biomassa final de 3,58 g/L, sendo esse resultado obtido 2,9 vezes maior que os valores obtidos na cultura fotoautotrófica.

A superfície de resposta para a produção de biomassa microalgal é apresentada na Figura 1, observa-se que existe uma tendência de encontrar uma faixa ótima de produção de biomassa nas condições do ponto central do experimento. 

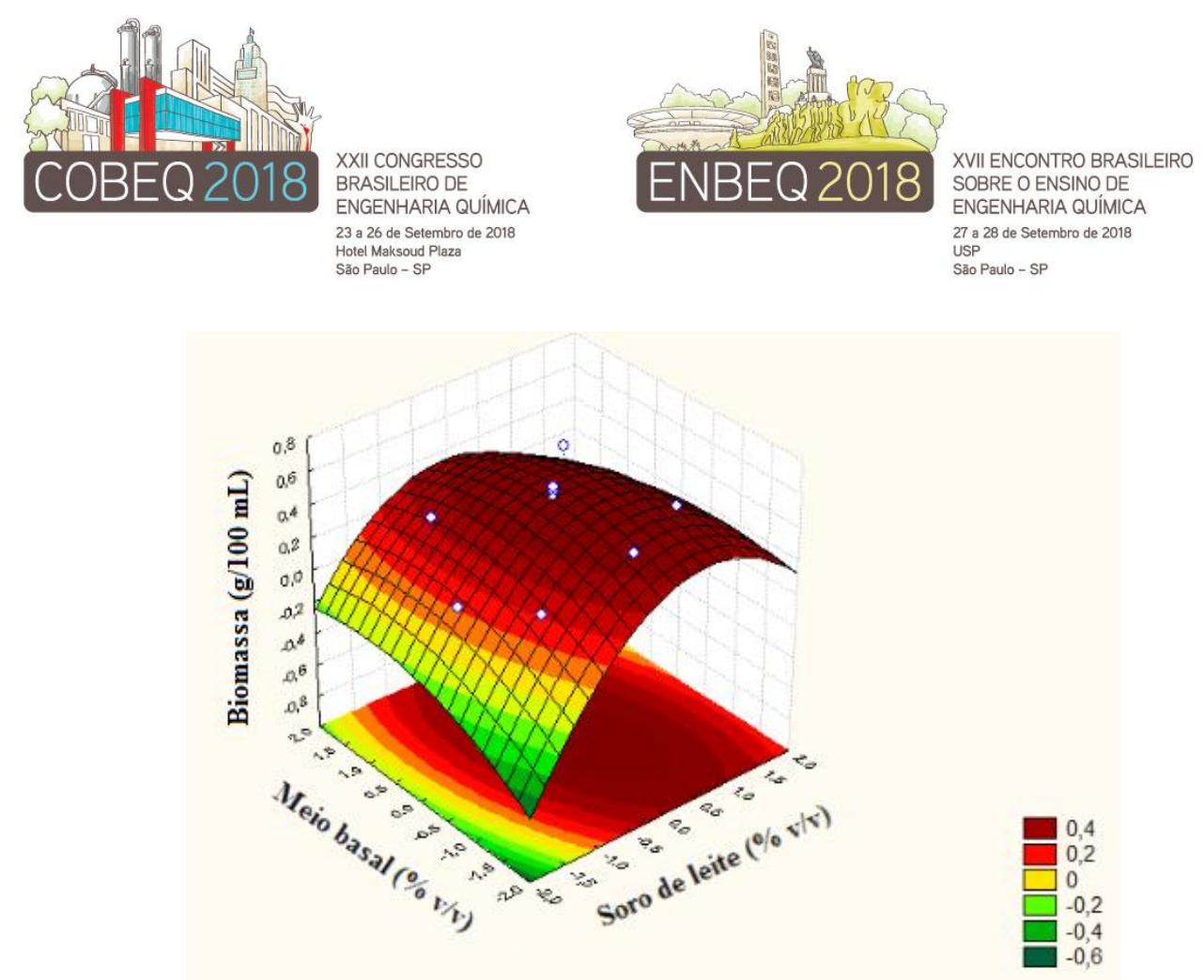

Figura 1 - Superfície de resposta apresentando a influência das concentrações de meio basal e de soro de leite na produção de biomassa microalgal de Chlorella sorokiniana.

Além disso, verifica-se que o crescimento da microalga promove a remoção de mais de $90 \%$ de lactose em todos os ensaios, indicando que a microalga de fato utiliza a lactose como fonte de carbono para o seu crescimento e consequentemente trata o efluente.

\section{CONSIDERAÇÕES FINAIS}

Os resultados obtidos sugerem que o soro de leite pode ser integrado às tecnologias de produção de biomassa de Chlorella sorokiniana e que o cultivo de microalgas pode ser aliado ao tratamento desse subproduto da indústria de laticínios. Além disso, os resultados mostraram que a utilização do soro de leite aumenta a produtividade de biomassa em relação aos cultivos fotoautotróficos tradicionais, além que o crescimento das microalgas promove a remoção da lactose presente no soro, a qual é responsável pela alta DQO do mesmo e é considerada o principal poluente do soro.

\section{REFERÊNCIAS}

ABREU, A. P.; FERnANDES, B.; VICENTE, A. A.; TEXEIRA, J.; DRAGONE, G. Mixotrophic cultivation of Chlorella vulgaris using industrial dairy waste as organic carbono source. Biosource Technology, v.118, p.61-66, 2012.

APHA. American Public Health Association. Standart Methods for the examination of water and wastewater. Baltimore: Port City, 1268 p., 2005.

MILLER, G. L. Use of dinitrosalicylic acid reagent for determination of reducing sugar. Analytical Chemistry, v. 31, p. 426, 1959.

SILVA, N. F. P. Crescimento de Microalgas em águas residuais: Produção de Biomassa e Remoção de Nutrientes. Porto: Mestrado integrado em Engenharia do Ambiente, 2014. 